\title{
Research on Information Ethics Problems and Countermeasures of E-commerce in the Era of Big Data
}

\author{
Xueyuan Wang, Jiajun Dang, and Wenyao Qu \\ School of Management Engineering, Zhengzhou University, No. 100 Science Street, Zhengzhou, china \\ 494900588@qq.com
}

Keywords: Information ethics; E-commerce; Big data

\begin{abstract}
In the era of big data, massive and precise data are obtained by network technology to promote the exchange of data and information in e-commerce. However, when the era of big data brings huge database for the development of e-commerce, some electronic commerce participants take a series of improper means in the process of using information, which triggers a series of information ethics problems. Firstly, this paper summarized the concept of information ethics problems in e-commerce activities under the era of big data, and then it elaborates the infringement of privacy and intellectual property rights problems, the problem of false information, illegal information exchange problems, and puts forward the countermeasures to provide a new way to solve the problems of information ethics in electronic commerce.
\end{abstract}

\section{INTRODUCTION}

Network technology under the era of big data promoting the exchange of data and then facilitate electronic commerce marketing, and the data will become more direct and effective information after screening and handling, which is a valuable resource in network marketing (Zhang Jie, Li Ke, 2014). Information accessing, copying and tracking has become more convenient and fast in the era of big data, so there are some e-commerce companies try to use abnormal channel to get access to the information which was not supposed to, the personal information is used for commercial purposes and the problem of spreading false information and so on seriously affected the safety, accuracy and reliability of the information. When consumers browse the website, the website will use the network technology to collect the consumer's personal information, and soon consumers will receive the relevant products advertises, telephones. On some ecommerce platforms, the phone, identity and address are easily leaked to interested businesses. Whether information is acquired, tracked or leaked, it has an impact on the consumer's personal life and even economic losses. This not only caused the social crisis of trust in e-commerce, but also posed challenges to the maintenance of information security in the big data environment (Hu Zhihui, 2015).

\section{THE CONNOTATION OF INFORMATION ETHICS IN E-COMMERCE ACTIVITIES}

Ethics is the guiding belief, standard or ideal of an individual or a group (Wang Qian, Zhu Hongfeng, Liu Tianhua, 2013). It is the standard and emotion of the good and evil formed by people in their daily life, and is not restricted by law. Information ethics refers to the ethics related to information activities. Under the influence of information technology, e-commerce activities should follow the ethical requirements, ethical standards and ethical rules in the process of information development, information dissemination, information management and utilization (Guo Kai, 2013).

\section{INFORMATION ETHICS PROBLEMS IN ELECTRONIC COMMERCE IN THE ERA OF BIG DATA}

With the support of huge data resources, many enterprises and businesses in e-commerce use unfair means to engage in business activities, It is mainly reflected in the information ethics problems caused by ecommerce enterprises in the process of information development, dissemination, information management and utilization: Infringement of privacy right, infringement of intellectual property rights, false information and illegal information transaction (Yang Likun, 2017).

\subsection{The infringement of privacy}

With the development of information technology, ecommerce companies are eager to obtain as much private information as possible for marketing or other purposes. In the era of big data, there are a large number of data, data types and other characteristics (Chen Yun, 2015), so e-commerce activities in the business want to use the data often involves a variety of consumer privacy. Richard T. De George divides privacy into six types: space privacy, physical / mental privacy, personal information privacy, communication privacy, personal privacy and computer privacy. The first kind of privacy advocates personal space is sacred and inviolable, namely personal space without any snooping or look right; second kinds of physical / mental privacy advocates people's physical and mental privacy and inviolable rights; The third kind of personal information privacy refers to the right to be held open other information except that it should be disclosed to the 
society; The fourth is communication privacy, which advocates that the activities between individuals are not overheard; The sixth is computer privacy, that is, personal activities on the computer (such as shopping online shopping behavior). The same thing about these privacy is that people can choose to show or not show their body, disclose or not disclose their information, communication content or ideas. Therefore, when people advocate a kind of privacy right, make others undertake a kind of obligation, that is, can not infringe this field. Usually in the public domain, people choose to make some of their information public, while in the private domain, they have the right to restrict others access to personal information, that is, the right to decide whether to disclose their information to the outside world. Therefore, the infringement of personal privacy without permission is intolerable both morally and legally.

Through the use of data warehouse, data mining processing technology can make businesses get more valuable information, the advantage of this behavior is that the enterprise can use this information for personalized services, but some enterprises take the most benefit, will take some improper means to obtain any of the mentioned privacy. According to the 2016 China Internet Association released the "Chinese protect the interests of Internet users report 2016" showed that nearly half $54 \%$ of Internet users believe that the personal information leakage, $84 \%$ of Internet users felt the adverse effects caused by the leakage of personal information(Ji Runbo, 2017).In China, some ecommerce businesses often exposure leak, there are even websites specializing in personal information, These websites not only steal our privacy by using information technology through illegal channels, but also subdivide the groups according to their own characteristics so as to sell information to them according to the customers' needs, for example, a 4S company can buy a large number telephone and other private information of people with higher consumption ability from such illegal websites.

The right of privacy is not only within the scope of the law, but also one of the ethical rights we should advocate. At present, both domestic and foreign pay more attention to the protection of consumer privacy, and in the era of big data, the protection of privacy should also put forward some new ethical requirements. Most of the use of computer and network users, the computer is more or less a black box, know how to use it, know how to run a variety of procedures, but the actual program design and encoding are absolutely ignorant of. When personal information is leaked, it is often in unknown state. Therefore, the protection of consumer privacy requires more government and enterprises to strengthen supervision.

\subsection{Infringement of intellectual property rights}

In the current big data environment, we should pay attention to the protection of intellectual property rights: copyright, patent and trademark. E-commerce is a digital transaction process; intellectual property rights are the main value components in the process of transaction. Ecommerce is developing with the sharing of data, which makes it contradictory with the protection of intellectual property rights, Therefore, the development of ecommerce will naturally be accompanied by a series of violations of intellectual property rights, and these problems are more serious than traditional business activities.

In recent years, the development of information technology has made it possible for businesses to steal information, and at the same time, it has encouraged piracy. In the online transactions, counterfeit products have become more and more pirated products. In today's rapid information exchange environment, the protection of intellectual property rights of users has become a challenge.

\subsection{False information problem}

In the era of big data, e-commerce businesses use information technology to provide consumers with more, more complete product data information. Guarantee product quality and service quality, whether for traditional business or e-commerce, is the fundamental guarantee for development. Information technology makes the provision of information is particularly important, businesses not only to ensure the authenticity of the information, accuracy, effectiveness, of course, to protect consumers' right to know the information. In last year's online transaction complaints, the most common complaint is the false information of goods.

The virtualization and informatization of e-commerce make enterprises and businesses pay more attention to the provision of information in order to win the greatest profits: what information and information are provided to consumers. Some businesses are opportunistic in providing information about goods. In the example of Taobao in many businesses will give their goods with "genuine" words and "high quality" labels to attract the attention of consumers, even by some landscaped pictures, other businesses making the commodity theft picture information is not true, many consumers mistakenly believe that cheap goods and then select in the business information to buy, some even uses pictures that beautify the picture, steal other businesses and make the products look good, many consumers browse through the information given by the business will mistakenly believe that the goods are cheap and fine, and then choose to buy.

Because of the network virtualization, consumers can not directly contact the goods, which requires the electricity supplier enterprises to ensure that the information is accurate and complete to safeguard our right to know. The spread of false information in today's online transactions should be stopped in time to ensure fair trading process.

\subsection{Information illegal transaction problem}

In the era of big data, consumer personal information has become a very valuable wealth, the value created by this information can bring huge market. Under the drive of interest, the consumer information is regarded as a commodity, and illegal transactions are growing in our country. In e-commerce, consumer information is acquired by e-commerce merchants and third party data or consulting companies. In e-commerce activities, to ensure the safety of information is the basic requirement 
of the development of big data era. However, the data holders in electronic commerce do not perform their obligations to protect the personal information security of the consumers, but use information to make improper profits. The illegal transaction of information reflects enterprises fail to performe the obligation that reasonable and legitimate access to and storage consumer information in e-commerce activities, this is the main manifestation of the lack of information ethics.

\section{COUNTERMEASURES OF SOLVING INFORMATION ETHICS PROBLEMS IN ELECTRONIC COMMERCE UNDER BIG DATA ENVIRONMENT}

The American scholar Richard T. De George pointed out: "Technology often develops faster than ethical theory, and the lag effect in this area often brings great harm to the people". Visible in the era of big data, the development of e-commerce should have profound ethical implications. We should not only pay attention to the information technology of the electronic commerce role, should also pay attention to the ethical practice, In the time lag effect of ethical culture and technology, efforts should be made to find a balance point to maintain the necessary tension between the two. Therefore, the participants in the development, acquisition and management of e-commerce information are duty bound to the ethical issues mentioned above.

\subsection{Strengthen the construction of information ethics}

First of all, starting from strengthening the construction of information ethics, and to arouse the attention of all walks of life to information security. Information technology provides a more efficient way for e-commerce enterprises to use information, develop information, management information, to a certain extent, whether the enterprise electronic commerce platform, businesses, and consumers are referred to as "information man", privacy infringement, intellectual property rights problem, problem of false information and illegal information trading problems belong to the problems in the use of process information. These problems arise from the behavior of information people, therefore, it is urgent to improve the ethical quality of information man, it is necessary to regulate the behavior of information man from the ethical point of view, so as to combine morality with morality, ethical requirements, ethical principles and ethical norms are should be put forward in such aspects as information development, information dissemination, information management and utilization.

Then consumer awareness of personal information protection should be enhanced, consumers should develop a good habit of surfing the Internet, to avoid browsing some hackers or bad websites, carefully select web pages and shopping software. Secondly, we should try to avoid providing personal sensitive information, and beware of information acquisition (Wang Xuelu, 2016). Finally, we can strengthen the security of personal information through the network technology, such as encryption and antivirus software to ensure the security of personal information.

E-commerce enterprises should also be based on the current application of various information problems, and actively improve the internal information standards, and strictly implement this specification, and actively promote the implementation of each employee in the enterprise, abide by. In addition, ethical construction within the enterprise is also important, such as the ethical code that matches e-commerce activities: honesty, respect and justice. At the same time, strengthen the information ethics education of the internal staff, make the whole staff pay attention to the information ethics problem.

\subsection{Strengthen the legal construction of information protection}

In China, the relevant laws and regulations on information technology ethics are being further explored and carried out( Wang Liming, 2013). There are some legislation about the protection of intellectual property rights : "Copyright law", "patent law", "Anti Unfair Competition Law", "Computer Software Protection Ordinance", "civil law", "electronic authentication service password management approach", "Selfregulation of online trading platform service", in addition, there are some laws and regulations to promote the development of e-commerce, the newly revised "law on the protection of consumer rights and interests" stipulates the legal obligations and related responsibilities to collect personal information. However, the above-mentioned legal provisions do not give special attention to the information behavior in the era of big data. Therefore, the relevant government departments should make the legal norms as soon as possible according to the characteristics of e-commerce activities. At present, scholars expect the improvement of the following information legal system: the legal system of information technology, the legal system of information industry, the legal system of information resources, the legal system of information property rights, etc.

\subsection{Strengthen information security supervision}

In the era of big data, e-commerce is developing rapidly, and the problem of information ethics appears frequently in e-commerce. The important reason is that the supervision of information activities in e-commerce is not strict. Practice has proved that in the context of large data age, the traditional information security technology has been difficult to adapt to large data development requirements (Wang Shiwei, 2016). First of all, the government should strengthen the supervision of information activities in e-commerce, grasp the market access, strengthen the monitoring efforts, and develop strict punitive measures. Second, government and electricity companies should strengthen the development of large data security technology, such as data encryption technology, information access control technology and data backup technology. Finally, to improve the ability of data protection, we should make full use of the technical advantages of big data to prevent information leakage, we can encrypt and protect the big data information on the key network nodes, establish a 
security protection system, and enhance the network information security defense capability.

\section{CONCLUSIONS}

This paper analyzes the information ethics problems in the process of information development, dissemination, information management and utilization in electronic commerce: infringement of privacy, infringement of intellectual property rights, false information, illegal information transactions. These ethical problems can be summed up as the security, accuracy and reliability of information. To fundamentally change these problems, we should first arouse people's attention to information security, accuracy and reliability, E-commerce enterprises should improve the relevant internal standards to regulate the use of information technology, and at the same time, through education to improve the level of information ethics of internal staff. Secondly, because of some improper information development, dissemination and use problems have touched the law, so the government should pay attention to improving the legal system of the relevant information, so as to provide strong measures to solve the information ethics problems. Finally, the government and e-commerce enterprises should use information technology to strengthen the supervision of information activities in e-commerce. These countermeasures are of great significance to promote the information security in the context of big data.

\section{ACKNOWLEDGEMENTS}

This research is supported by National Natural Science Foundation of China (Grant No. U1604150), Humanities \& Social Sciences Research Foundation of Ministry of Education of China (Grant No. 15YJC630148), Distinguished Young Teacher Development Foundation of Zhengzhou University (1421326092), and Key Research Foundation of University Education in Henan province (17A520058). The authors would like to thank the editors and anonymous referees for their careful and fruitful comments to improve the quality of this paper.

\section{REFERENCES}

[1] Ji Runbo, 2017. Personal information protection in the era of big data, Telecommunications Network Technology. (4), pp.53-56.

[2] Chen Yun, 2015. Information security problems and Countermeasures in the era of big data, Electronic Technology \& Software Engineering. (23), pp.212-213.

[3] Wang Xuelu, 2016. Information security problems and Countermeasures in the era of big data, China New Telecommunications. (5), pp.93.

[4] Wang Shiwei, 2016. New features and new requirements of information security in the era of big data, Library and Information Service.60(6), pp.5-14.

[5] Yang Likun, 2017. The protection of personal information right in the era of big data, Bosom Friend Inspiration. (4), pp.230-231.

[6] Wang Qian, Zhu Hongfeng, Liu Tianhua, 2013. Current situation and development of big data security, Computer \& Network. (16), pp.66-68.

[7] Wang Liming, 2013.On the legal protection of personal information right -- centered on the division of personal information right and privacy right, Modern Law Science. 35(4), pp.65-72.

[8] Hu Zhihui, 2015. The protection of personal information by the government in the era of big data, Theoretical Exploration. (3), pp.103-107.

[9] Zhang Jie, Li Ke, 2014. Research on business ethics of ecommerce in China, Journal of Shandong Institute of Business and Technology. 28(4), pp.74-77.

[10] Guo Kai, 2013. Thoughts on the ethical construction of ecommerce enterprises in China, Productivity Research. (8), pp.165-166. 